\title{
Postoperative atrial fibrillation does not impact on overall survival after esophagectomy in patients with thoracic esophageal cancer: results from a randomized, double-blind, placebo-controlled trial
}

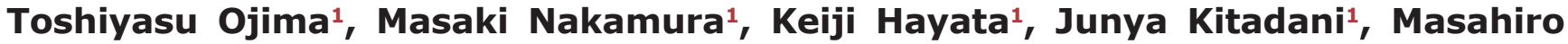 \\ Katsuda ${ }^{1}$, Mikihito Nakamori ${ }^{1}$, Akihiro Takeuchi ${ }^{1}$, Shimpei Maruoka ${ }^{1}$, Naoki Fukuda ${ }^{1}$, \\ Shinta Tominaga ${ }^{1}$, Hideki Motobayashi ${ }^{1}$ and Hiroki Yamaue ${ }^{1}$ \\ ${ }^{1}$ Second Department of Surgery, Wakayama Medical University, Wakayama, Japan \\ Correspondence to: Toshiyasu Ojima, email: tojima@wakayama-med.ac.jp
}

Keywords: esophageal cancer; atrial fibrillation; landiolol; randomized controlled trial; complication

Received: April 25, $2020 \quad$ Accepted: June 01, $2020 \quad$ Published: June 23, 2020

Copyright: Ojima et al. This is an open-access article distributed under the terms of the Creative Commons Attribution License 3.0 (CC BY 3.0), which permits unrestricted use, distribution, and reproduction in any medium, provided the original author and source are credited.

\section{ABSTRACT}

Background: Administration of landiolol hydrochloride was found to be associated with reduced incidence of atrial fibrillation (AF) after esophagectomy for esophageal cancer in our previous randomized controlled trial (RCT). In addition, reduced incidence of AF was associated with reduction of other complications. Meanwhile, the effects of postoperative AF and other complications on long-term survival following esophagectomy are not well understood.

Materials and Methods: Between March 2014 and January 2016, 100 patients with esophageal cancer were registered in an RCT trial and randomly allocated to receive either administration of landiolol or a placebo. We analyzed data from this RCT to better understand the effect of postoperative AF and severe associated complications on overall survival (OS) after esophagectomy for cancer. We also examined whether prophylactic administration of landiolol hydrochloride directly affects prolonged survival in patients with esophageal cancer.

Results: The five-year rates of OS in the patients with and without AF were $60 \%$, and $68.6 \%$, respectively, there was no significant difference $(P=0.328)$. Five-year rates of OS of the patients with and without severe complications were $64.6 \%$, and $67.5 \%$, respectively $(P=0.995)$. The five-year rates of OS in the placebo and landiolol groups were $65.8 \%$ and $68 \%$, respectively $(P=0.809)$. In multivariate analysis, high stage (stage III/IV) alone was an independent prognostic factor for esophageal cancer patients following esophagectomy.

Conclusions: New-onset AF and the other severe complications were not associated with poorer long-term survival following esophagectomy. In addition, administration of landiolol hydrochloride after esophagectomy did not contribute to prolonging the OS.

\section{INTRODUCTION}

Esophagectomy is considered the optimum treatment against esophageal cancers. Despite improvements in surgical skills and the introduction of minimally invasive surgery, such as thoracoscopic esophagectomy, the overall rate of morbidity remains very high.

New-onset atrial fibrillation (AF) following esophagectomy occurs in $10-40 \%$ of patients with esophageal cancer [1-4]. Postoperative AF may directly increase the risk of thromboembolic events and is also known to indirectly increase rates of other complications, such as anastomotic leakage, pneumonia, and respiratory failure, through organ hypoperfusion [5-7]. The incidence of major postoperative complications in our previous study increased in patients that developed new-onset AF following subtotal esophagectomy [7]. Strategies targeting prevention of $\mathrm{AF}$ after esophagectomy may therefore be valuable. 
Landiolol hydrochloride is an ultra-short acting beta 1-selective blocker that can be administered intravenously. It has a half-life of only four minutes and it has a weaker negative inotropic effect than other intravenous beta 1-blockers [8-10]. We performed a randomized, double-blind, placebo-controlled comparative phase III trial (UMIN000010648) to examine if intravenous administration of landiolol hydrochloride is effective in the prevention of AF after esophagectomy. We also examined if reduced incidence of AF may reduce other postoperative complications. Administration of landiolol hydrochloride had association in our previous study with reduced incidence of AF after esophagectomy for esophageal cancer. This was associated with reduction in other postoperative complications [8].

The influences of new-onset AF after esophagectomy on long-term survival have not been widely studied. Two papers reported no significant impact on three-year survival $[4,5]$; while another two papers considered new-onset AF after esophagectomy to be an independent factor in poor prognosis $[11,12]$. The effect of postoperative AF on long-term survival following esophagectomy is therefore controversial.

Severe postoperative complications may make patients with esophageal cancer less likely to survive over the long term. Patients with esophageal cancer but without severe postoperative complications have been shown to have better long-term survival than patients with complications [13-15]. Elsewhere, no such relationship was shown between severe complications and long-term survival [16-19].

The current study uses our randomized controlled trial (RCT) data to investigate the effect of postoperative AF on long-term oncological outcomes following transthoracic esophagectomy for cancer. We also evaluate the influence of severe postoperative complications on overall survival (OS) and whether prophylactic administration of landiolol hydrochloride directly influences prolonged survival in patients with esophageal cancer.

\section{RESULTS}

\section{Patients characteristics and surgical outcomes}

Table 1 shows patient characteristics. There were no significant differences between the two groups in age, gender, body mass index, percentage of patients receiving neoadjuvant chemotherapy, tumor location, pathological type of tumors, or Tumor-Node-Metastasis (TNM) stage. Table 2 shows surgical outcomes, with no differences between the two groups, which were well balanced.

\section{Postoperative complications}

New-onset AF was noted in 15 patients in the placebo group and in five patients in the landiolol group
(Table 2). There were significant differences $(P=0.012)$. Overall incidence of postoperative complications of more than Clavien-Dindo Grade IIIa were significantly higher in the placebo group (32\%) than in the landiolol group $(8 \%)(P=0.003)$.

\section{Recurrence of tumors}

Median follow-up periods in the placebo and landiolol groups were 60.5 months and 58 months, respectively. The percentage of patients receiving adjuvant chemotherapy was similar between the two groups. Fourteen patients in the placebo group and 13 patients in the landiolol group had recurrence of esophageal cancer $(P=0.822$, Table 3$)$. Table 3 shows the details of the recurrent patients. These 27 patients received chemotherapy, chemoradiotherapy or palliative surgery, and four patients survive at the time of writing.

\section{Follow-up data of the patients with stage I, II}

Table 4 shows the recurrence rates and mortality rates in the patients with stage I and II. When limited to the patients with stage I and II, the recurrence rates in the patients with and without AF were $15 \%$, and $9 \%$, respectively $(P=0.611)$. However, overall mortality rate was significantly higher in the patients with AF $(39 \%)$ than in the patients without AF $(14 \%)(P=0.046)$.

\section{Survival outcomes}

Figure 1 shows Kaplan-Meier curves of OS stratified by TNM stage. The five-year rates of OS in patients with stage I, II, and III / IV were $85.9 \%, 76.2 \%$, and $46.5 \%$, respectively $(P=0.001)$.

Figure 2 shows Kaplan-Meier curves of OS stratified by the presence or absence of postoperative AF. The five-year OS rates in all patients with and without AF were $60 \%$, and $68.6 \%$, respectively, there were no significant differences in the OS rates between the two groups (Figure $2 \mathrm{~A}, P=0.328$ ). In stage I/II stratification, there were significant differences in the rates of OS between the two groups (Figure $2 \mathrm{~B}, P=0.045$ ), but in stage III / IV stratification there were no significant differences (Figure 2C, $P=0.929$ ).

Figure 3 shows Kaplan-Meier curves of OS stratified by the presence/absence of postoperative complications (more than Clavien-Dindo grade IIIa). Five-year rates of OS in the patients with and without postoperative complications were $64.6 \%$, and $67.5 \%$, respectively. There was no significant difference in the rates of OS between the two groups $(P=0.995)$.

Figure 4 shows intention to treat Kaplan-Meier curves of OS between the placebo and the landiolol groups. Five-year OS rates in the placebo and landiolol groups were $65.8 \%$, and $68 \%$, respectively. There was no 
Table 1: Clinicopathological characteristics of the patients

\begin{tabular}{|c|c|c|c|}
\hline Variable & Placebo $(n=50)$ & Landiolol $(n=50)$ & $P$ value \\
\hline \multicolumn{4}{|l|}{ Clinical characteristics } \\
\hline Age, years & $69(45-83)$ & $68(31-85)$ & 0.782 \\
\hline Gender, Male/Female & $41 / 9$ & $36 / 14$ & 0.235 \\
\hline BMI, $\mathrm{kg} / \mathrm{m}^{2}$ & $22(16-29)$ & $22(13-37)$ & 0.837 \\
\hline Neoadjuvant chemotherapy & $19(38 \%)$ & $27(54 \%)$ & 0.108 \\
\hline Docetaxel + Cisplatin +5 -FU & 7 & 16 & \\
\hline Docetaxel + Cisplatin $+\mathrm{S}-1$ & 12 & 11 & \\
\hline \multicolumn{4}{|l|}{ Pathological characteristics } \\
\hline Tumor location, U/M/L & $7 / 27 / 16$ & $8 / 26 / 16$ & 0.958 \\
\hline Pathological type (scc/adeno/other) & $45 / 3 / 2$ & $46 / 3 / 1$ & 0.842 \\
\hline TNM stage*, I/II/III/IV & $19 / 10 / 20 / 1$ & $17 / 11 / 21 / 1$ & 0.980 \\
\hline
\end{tabular}

*Tumor-Node-Metastasis (TNM) Classification of the International Union Against Cancer (UICC), seventh edition. Abbreviations: BMI, body mass index; 5-FU, 5- fluorouracil; U, upper third thorax; M, middle third thorax; L, lower third thorax; scc, squamous cell carcinoma; adeno, adenocarcinoma.

\section{Table 2: Surgical outcomes}

\begin{tabular}{lccc}
\hline Variable & Placebo $(\boldsymbol{n}=\mathbf{5 0})$ & Landiolol $(\boldsymbol{n}=\mathbf{5 0})$ & $\boldsymbol{P}$ value \\
\hline Surgical outcomes & & & \\
Lymph node dissection, three-field/two-field & $16 / 34$ & $19 / 31$ & 0.529 \\
Total duration of surgery, min & $473(311-606)$ & $457(355-609)$ & 0.597 \\
Blood loss, ml & $70(10-435)$ & $115(30-655)$ & 0.065 \\
Blood transfusion & $4(8 \%)$ & $8(16 \%)$ & 0.357 \\
R0 curative resection & $48(96 \%)$ & $48(96 \%)$ & 0.999 \\
Complications & & & \\
Atrial fibrillation & $15(30 \%)$ & $5(10 \%)$ & 0.012 \\
All complication, more than grade $\mathrm{III}^{* *}$ & $16(32 \%)$ & $4(8 \%)$ & 0.003 \\
Mortality & 0 & 0 & 0.999 \\
\hline
\end{tabular}

*Three-field indicates bilateral cervical regions, mediastinal spaces and abdomen; two-field indicates mediastinum and abdomen. ${ }^{* *}$ Surgical complications were classified into five categories according to the Clavien-Dindo classification.

\section{Table 3: Oncological outcomes}

\begin{tabular}{lccc}
\hline Variable & Placebo $(\boldsymbol{n}=\mathbf{5 0})$ & Landiolol $(\boldsymbol{n}=\mathbf{5 0})$ & $\boldsymbol{P}$ value \\
\hline Follow-up periods, months & $60.5(4-83)$ & $58(6-84)$ & 0.691 \\
Adjuvant chemotherapy & $10(20 \%)$ & $9(18 \%)$ & 0.799 \\
S-1 & 2 & 3 & \\
Paclitaxel & 2 & 3 & \\
Docetaxel + Cisplatin + S-1 & 2 & 1 & \\
5-FU + Cisplatin & 2 & 1 & \\
5-FU + Cisplatin + radiation & 2 & 0 & \\
CPT-11 + Cisplatin & 0 & 1 & \\
Recurrence & $14(28 \%)$ & $13(26 \%)$ & \\
First recurrence site, & & & \\
LN/lung/liver/bone/others & $5 / 5 / 1 / 1 / 2^{*}$ & $7 / 3 / 2 / 1 / 0$ & \\
TNM stage**, I/II/III/IV & $2 / 1 / 11 / 0$ & $1 / 2 / 10 / 0$ & \\
\hline
\end{tabular}

"One skin metastasis and 1 brain metastasis. ${ }^{* *}$ Tumor-Node-Metastasis (TNM) Classification of the International Union Against Cancer (UICC), seventh edition. Abbreviations: 5-FU, 5- fluorouracil; CPT-11, irinotecan; LN, lymph node. 
Table 4: Follow-up data of the patients with stage I, II

\begin{tabular}{llll}
\hline Variable & Patients with AF $(\boldsymbol{n}=\mathbf{1 3})$ & Patients without AF $(\boldsymbol{n}=\mathbf{4 4})$ & $\boldsymbol{P}$ value \\
\hline Recurrence & $2(15 \%)$ & $4(9 \%)$ & 0.611 \\
Overall mortality & $5(39 \%)$ & $6(14 \%)$ & 0.046 \\
Cancer-specific mortality & $2(15 \%)$ & $3(7 \%)$ & \\
Mortality of other diseases & $3(23 \%)$ & $3(7 \%)$ & \\
\hline
\end{tabular}

Abbreviations: AF, atrial fibrillation.

significant difference in the rates of OS between the two groups $(P=0.809)$.

\section{Univariate and multivariate Cox proportional hazard model analysis for OS}

Univariate and multivariate OS analyses were calculated using Cox proportional hazard regression model. In univariate analysis, 3 of the 13 factors decreased OS in patients with esophageal cancer following esophagectomy (Table 5, $P<0.10$ ). The factors were diabetes, patients who underwent curative resection, and patients with TNM stage III/IV. Multivariate analysis revealed that among patients with esophageal cancers following esophagectomy, only the patients with TNM stage III/IV $(P=0.001$; hazards ratio, 3.413) were independent associative factors for decreased OS (Table 5).

\section{DISCUSSION}

In our prospective RCT, administration of landiolol was associated with reduction in incidence of new-onset AF following esophagectomy for esophageal cancer.
Furthermore, reduction in the incidence of AF related to landiolol administration was associated with reduction in the incidence of the other severe postoperative complications [8].

New-onset AF was unrelated, however, to poorer long-term survival after esophagectomy. When limited to stage I and II patients with esophageal cancer, the occurrence of AF after esophagectomy may have an association with poor survival. Therefore, the prophylactic administration of landiolol hydrochloride may prolong the overall survival in patients with stage I and II. Contrary to previous reports [13-15], overall severe complications were not associated with long-term survival of these patients. This study refuted the hypothesis that administration of landiolol hydrochloride leads to improvement of long-term oncological outcomes after esophagectomy for esophageal cancer. Only high stage of cancer (stage III/IV) was an independent prognostic factor for patients with esophageal cancer following esophagectomy.

New-onset AF after esophagectomy is due to the preexisting cardiac substrate conducive to the activation of AF. This reflects long-standing cardiac remodeling

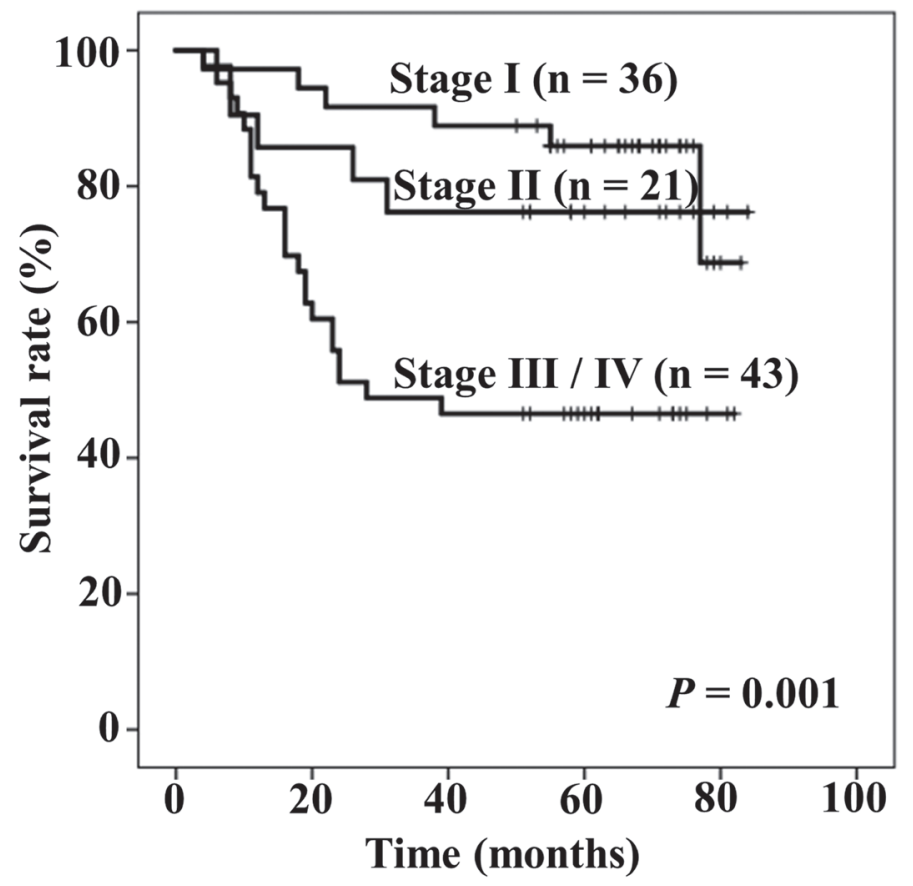

Figure 1: Kaplan-Meier curves of overall survival stratified by Tumor-Node-Metastasis (TNM) stage. 
Table 5: Univariate and multivariate Cox proportional hazard model analysis for overall survival

\begin{tabular}{|c|c|c|c|c|c|}
\hline \multirow[b]{2}{*}{ Risk factors } & \multirow[b]{2}{*}{ Categories } & \multicolumn{2}{|c|}{ Univariate analysis } & \multicolumn{2}{|c|}{ Multivariate analysis } \\
\hline & & $P$ & $\begin{array}{l}\text { Hazards ratio } \\
(95 \% \mathrm{CI})\end{array}$ & $\boldsymbol{P}$ & $\begin{array}{l}\text { Hazards ratio } \\
(95 \% \mathrm{CI})\end{array}$ \\
\hline \multirow[t]{2}{*}{ Hypertension } & yes & 0.479 & $0.781(0.394-1.548)$ & & \\
\hline & no & & & & \\
\hline \multirow[t]{2}{*}{ Diabetes mellitus } & yes & 0.022 & $2.369(1.131-4.961)$ & 0.067 & $2.067(0.950-4.496)$ \\
\hline & no & & & & \\
\hline \multirow[t]{2}{*}{ Old myocardial infarction } & yes & 0.981 & $0.976(0.133-7.164)$ & & \\
\hline & no & & & & \\
\hline \multirow[t]{2}{*}{ COPD } & yes & 0.153 & $0.421(0.129-1.379)$ & & \\
\hline & no & & & & \\
\hline \multirow[t]{2}{*}{ Smoking } & yes & 0.346 & $1.533(0.631-3.727)$ & & \\
\hline & no & & & & \\
\hline \multirow[t]{2}{*}{ Daily drinker } & yes & 0.990 & $0.994(0.411-2.403)$ & & \\
\hline & no & & & & \\
\hline \multirow[t]{2}{*}{ Ejection fraction } & $60 \%<$ & 0.870 & $1.066(0.497-2.286)$ & & \\
\hline & $60 \% \geq$ & & & & \\
\hline \multirow[t]{2}{*}{ TNM stage* } & III/IV & 0.001 & $3.647(1.771-7.509)$ & 0.001 & $3.413(1.633-7.135)$ \\
\hline & $\mathrm{I} / \mathrm{II}$ & & & & \\
\hline \multirow[t]{2}{*}{ Blood transfusion } & yes & 0.526 & $1.360(0.526-3.517)$ & & \\
\hline & no & & & & \\
\hline \multirow[t]{2}{*}{$\mathrm{R} 0^{*}$ curative resection } & yes & 0.052 & $3.258(0.989-10.731)$ & 0.596 & $1.409(0.397-5.002)$ \\
\hline & no & & & & \\
\hline \multirow[t]{2}{*}{ Postoperative atrial fibrillation } & yes & 0.334 & $1.457(0.679-3.124)$ & & \\
\hline & no & & & & \\
\hline \multirow{2}{*}{$\begin{array}{l}\text { Postoperative complications } \\
\text { (more than Grade IIIa**) }\end{array}$} & yes & 0.995 & $0.997(0.434-2.291)$ & & \\
\hline & no & & & & \\
\hline \multirow[t]{2}{*}{ Assignment group } & Placebo & 0.810 & $0.921(0.469-1.809)$ & & \\
\hline & Landiolol & & & & \\
\hline
\end{tabular}

${ }^{*}$ Tumor-Node-Metastasis (TNM) Classification of the International Union Against Cancer (UICC), seventh edition. ${ }^{* *}$ Surgical complications were classified into five categories according to the Clavien-Dindo classification. Abbreviations: CI, confidence interval; COPD, chronic obstructive pulmonary disease.

and represents overall cardiovascular risk independent of acute onset of postoperative AF $[12,20]$. Postoperative AF may therefore be correlated with long-term survival following esophagectomy $[11,12]$. This hypothesis was not substantiated in the current study, however, which included patients in all stages. Patients with AF after esophagectomy may have increased risk of chronic AF in the future, and may have increased post-operative mortality, such as by thromboembolism, stroke or heart failure $[12,20]$. In the current study, however, none of the patients who had new-onset AF after esophagectomy developed chronic AF. To better understand the relationship between new-onset AF after esophagectomy and long-term survival, clarification by large-scale multicenter clinical trials is required.
The influence of severe postoperative complications on the long-term survival of patients with esophageal cancer remains controversial [13-19]. In our results, there were no differences in survival rates between patients with and without severe complications. Severe complications, such as anastomotic leakage, pulmonary complications and bilateral vocal code paralysis, may impact on shortterm surgical outcomes through a pathway of systemic inflammatory response. Long-term survival, however, may not be affected after the short-term surgical effect has disappeared [16]. There were no mortalities during this RCT, which was based in a high-volume center. In addition, the rate of severe complication (more than Clavien-Dindo grade IIIa) was low at 20\%. All patients went through the same standardized multidisciplinary 
team process and were treated in a high-volume center. In general, patients with esophageal cancer who undergo esophagectomy in high-volume centers have been shown to have improved short- and long-term outcomes [15].

Invasion due to esophagectomy induces an increase in inflammatory cytokines. Perioperative inflammation is generally accepted to be related to tumor recurrence $[8,21,22]$. Landiolol hydrochloride has strong antiinflammatory effects, it therefore not only reduces postoperative complication rates, but may also help to reduce tumor recurrence after esophagectomy [8]. Indeed, beta-blockers in general have been reported to improve prognosis for various cancers [23-27]. The antitumor effect exerted by beta-blockers may be mediated by suppression of the sympathetic nervous system through blocking of catecholamines [22]. This RCT has already proven a significantly lower serum IL-6 level in the landiolol group than in the placebo group during the early postoperative period [8]. In addition, landiolol hydrochloride may inhibit attachment of circulating tumor cells to vascular endothelial cells $[21,28]$. In this study, however, the recurrence and survival rates were similar with and without administration of landiolol. In addition, there was no significant difference in the rates of relapse-free survival between the two groups (logrank $P=0.661$, data not shown). In our study, $3 \mu \mathrm{g} / \mathrm{kg} /$ min dose of landiolol was administered only during the $72 \mathrm{hr}$ after esophagectomy. In previous papers, beta blockers improved prognosis for various cancers, but were administered over a long-term period [23-27]. To confirm whether prophylactic administration of landiolol directly influences prolonged survival in patients with esophageal cancer after esophagectomy, the dose and the duration of landiolol require examination.

This study had several limitations. First, due to the relatively small sample size $(n=100)$, findings from this study could not establish definitive evidence. It was also a single-center study. Multi-center large scale prospective RCT to evaluate whether intravenous administration of landiolol hydrochloride affects long-term survival after esophagectomy for esophageal cancer is therefore required. A second limitation is that the median follow-up period in this study was 60 months, so a longer follow-up period is needed. Thirdly, subsequent treatment after esophageal cancer recurrence was not defined, so differences in treatment after recurrence may have affected survival analysis.

In conclusion, new-onset $\mathrm{AF}$ and other severe complications were not associated with poorer long-term
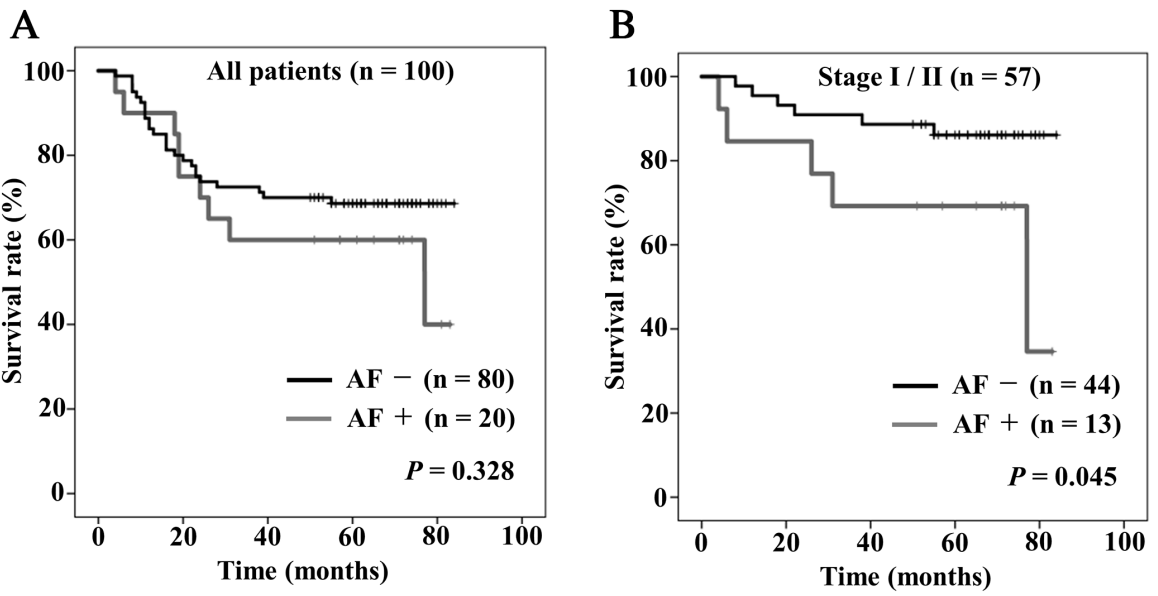

C

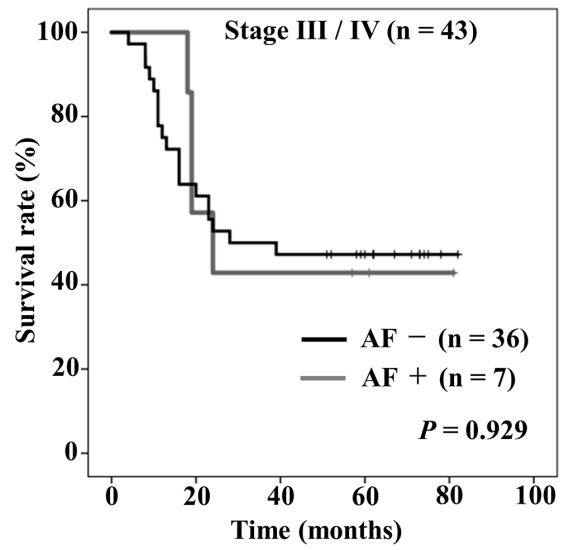

Figure 2: Kaplan-Meier curves of overall survival stratified by the presence (gray) or absence (black) of postoperative atrial fibrillation (AF). (A) All patients, (B) stage I/II, (C) stage III/IV. 


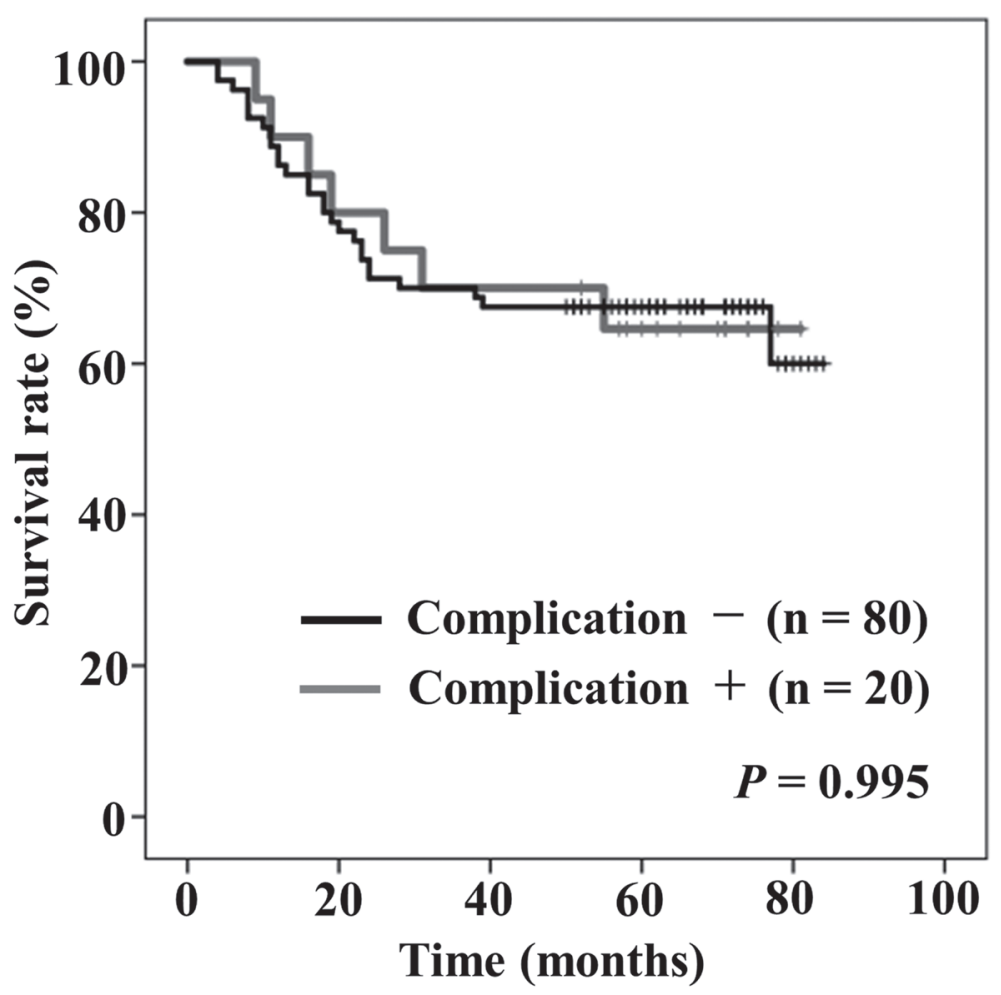

Figure 3: Kaplan-Meier curves of overall survival stratified by the presence (gray) or absence (black) of postoperative complication (more than Clavien-Dindo classification grade IIIa).

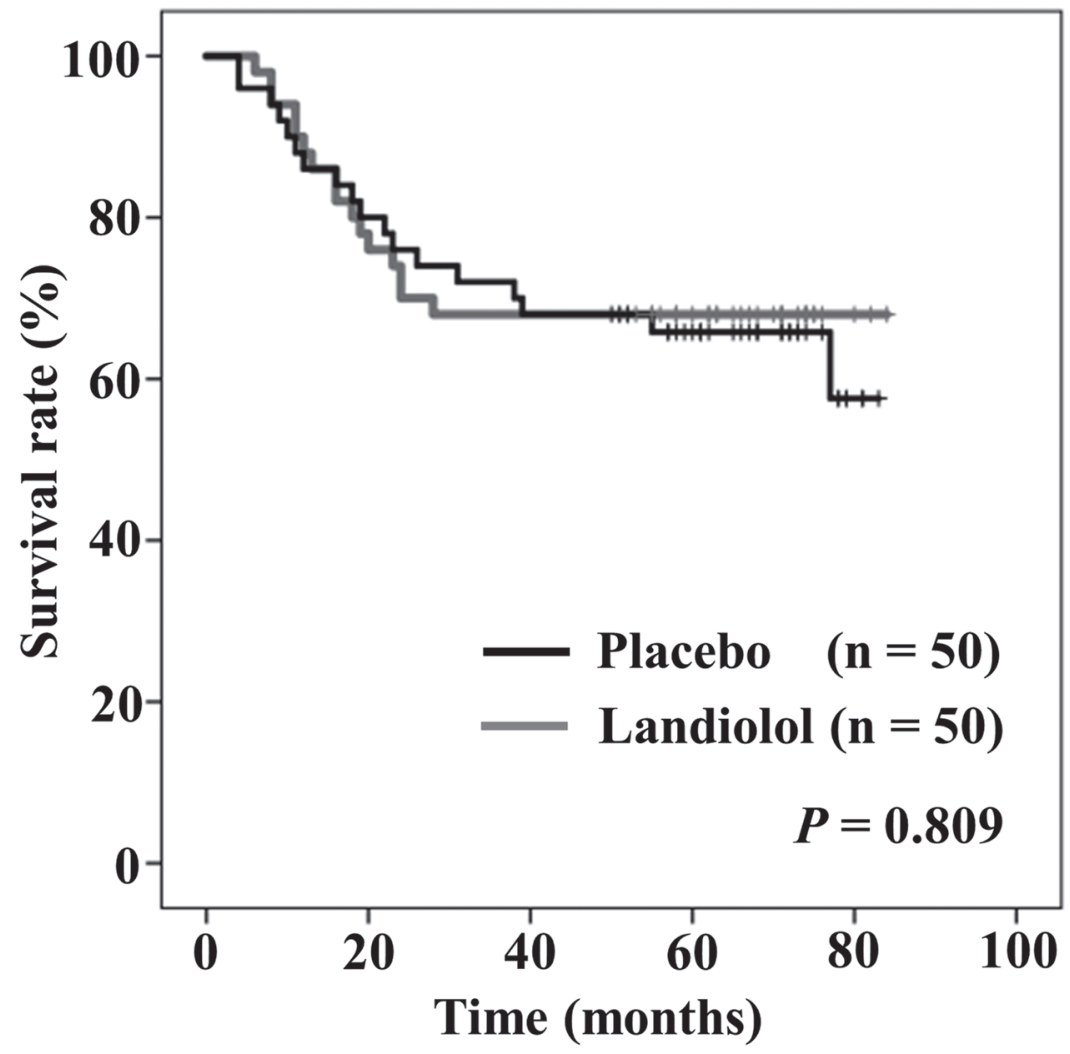

Figure 4: Intention to treat Kaplan-Meier curves of overall survival between placebo (black) and landiolol (gray) groups. 
survival after esophagectomy. In addition, administration of landiolol hydrochloride after esophagectomy did not contribute to prolonged OS of patients with esophageal cancer.

\section{MATERIALS AND METHODS}

\section{Study population}

Participants of this study were patients with diagnosed esophageal cancer at the Wakayama Medical University Hospital (WMUH). Detailed inclusion criteria are described in our previous paper [8]. This was a randomized, double-blind, placebo-controlled comparative phase III trial [8], conducted in accordance with a protocol reviewed and approved by the WMUH Ethical Committee on Human Research (approval number 1235). The study protocol was registered at the University Hospital Medical Information Network (UMIN000010648).

\section{Randomization and blinding}

Between March 2014 and January 2016, the 100 patients registered in the study were randomly allocated to receive administration of either landiolol or a placebo. After transthoracic esophagectomy with systematic lymphadenectomy, patients were randomized on postoperative day 1 in accordance with the study protocol. Infusion of landiolol hydrochloride (Ono Pharmaceutical, Osaka, Japan) was started at $3 \mu \mathrm{g} / \mathrm{kg} / \mathrm{min}$ for 72 hours. Glucose solution was administered at $3 \mathrm{~mL} / \mathrm{hr}$ during the same period. Patients, medical staff and investigators were all blinded to the treatments except one clinical research coordinator in the central registry and two selected pharmacists in WMUH who were aware of the treatments.

\section{Study endpoints}

The primary end point of this RCT was the incidence of AF after esophagectomy. Secondary endpoints were incidence of all postoperative complications and OS.

AF was defined as an absent $\mathrm{P}$ wave before the QRS complex, with irregular ventricular rhythm shown on 12-lead electrocardiogram [3, 7, 8]. Occurrence of postoperative AF was defined as persistence of this arrhythmia for five minutes or more. Diagnosis of AF was re-confirmed by cardiologists. Postoperative complications were analyzed according to Clavien-Dindo classification [29].

\section{Follow-up and additional treatments}

For stage I/II patients who underwent R0 resection, follow-up with semiannual endoscopy and abdominal computed tomography were performed. We used adjuvant chemotherapy for patients that were higher than stage III.
For patients who had undergone $\mathrm{R} 1$ resection, additional chemoradiotherapy was recommended, but we chose the same kind of follow-up for cases where this was considered to be impossible because of severe coexisting diseases. Subsequent treatment was not defined in the case of recurring esophageal cancer.

\section{Statistical analysis}

SPSS 22.0 software program (SPSS Inc., Chicago, IL) was used for all statistical analyses. Quantitative results are expressed as medians and ranges. Statistical comparisons between the placebo group and the landiolol group were performed with $\chi^{2}$ statistics and Fisher's exact test; $P<0.05$ was considered significant. OS was defined as the time from the esophagectomy to the date of death from any cause. Survival curves were generated using the Kaplan-Meier method and compared using the logrank test; $P<0.05$ was considered significant. Univariate and multivariate Cox proportional hazard models were used to evaluate factors that independently affected OS. Factors associated with univariate $P<0.10$ were included in the multivariate analysis, while factors associated with multivariate $P<0.05$ were defined as independent factors associated with OS.

\section{Abbreviations}

AF: atrial fibrillation; RCT: randomized controlled trial; OS: overall survival; TNM: Tumor-Node-Metastasis; WMUH: Wakayama Medical University Hospital.

\section{Author contributions}

Study concept and design: Ojima and Yamaue. Acquisition of data: Ojima, Nakamura, Hayata, Kitadani, Katsuda, Nakamori, Takeuchi, Maruoka, Fukuda, Tominaga, and Motobayashi. Analysis and interpretation of data: Ojima, Nakamura, Hayata and Nakamori. Drafting of the manuscript: Ojima, Nakamura and Katsuda. Critical revision of the manuscript for important intellectual content: Yamaue. Statistical analysis: Ojima, Nakamura and Yamaue. Administrative, technical and material support: Nakamura, Hayata and Yamaue. Study supervision: Yamaue.

\section{ACKNOWLEDGMENTS}

We acknowledge proofreading and editing by Benjamin Phillis at the Clinical Study Support Center, Wakayama Medical University.

\section{Ethics statement}

Informed consent was obtained from all patients in accordance with the guidelines of the Wakayama 
Medical University Hospital Ethics Committee on Human Research. The study protocol was registered in the University Hospital Information Network Center in Japan (UMIN000010648).

\section{CONFLICTS OF INTEREST}

The authors declare that they have no conflicts of interests.

\section{FUNDING}

This research did not receive any specific grant from funding agencies in the public, commercial, or not-forprofit sectors.

\section{REFERENCES}

1. Blencowe NS, Strong S, McNair AG, Brookes ST, Crosby T, Griffin SM, Blazeby JM. Reporting of short-term clinical outcomes after esophagectomy: a systematic review. Ann Surg. 2012; 255:658-666. https://doi.org/10.1097/ SLA.0b013e3182480a6a. [PubMed]

2. Low DE, Alderson D, Cecconello I, Chang AC, Darling GE, D'Journo XB, Griffin SM, Hölscher AH, Hofstetter WL, Jobe BA, Kitagawa Y, Kucharczuk JC, Law SY, et al. International Consensus on Standardization of Data Collection for Complications Associated With Esophagectomy: Esophagectomy Complications Consensus Group (ECCG). Ann Surg. 2015; 262:286-294. https://doi. org/10.1097/SLA.0000000000001098. [PubMed]

3. Vaporciyan AA, Correa AM, Rice DC, Roth JA, Smythe WR, Swisher SG, Walsh GL, Putnam JB Jr. Risk factors associated with atrial fibrillation after noncardiac thoracic surgery: analysis of 2588 patients. J Thorac Cardiovasc Surg. 2004; 127:779-786. https://doi.org/10.1016/j. jtcvs.2003.07.011. [PubMed]

4. Mc Cormack O, Zaborowski A, King S, Healy L, Daly C, O'Farrell N, Donohoe CL, Ravi N, Reynolds JV. New-onset atrial fibrillation post-surgery for esophageal and junctional cancer: incidence, management, and impact on short- and long-term outcomes. Ann Surg. 2014; 260:772-778. https:// doi.org/10.1097/SLA.0000000000000960. [PubMed]

5. Murthy SC, Law S, Whooley BP, Alexandrou A, Chu $\mathrm{KM}$, Wong J. Atrial fibrillation after esophagectomy is a marker for postoperative morbidity and mortality. J Thorac Cardiovasc Surg. 2003; 126:1162-1167. https://doi. org/10.1016/S0022-5223(03)00974-7. [PubMed]

6. Stippel DL, Taylan C, Schröder W, Beckurts KT, Hölscher AH. Supraventricular tachyarrhythmia as early indicator of a complicated course after esophagectomy. Dis Esophagus. 2005; 18:267-273. https://doi.org/10.1111/j.1442-2050.2005.00487.x. [PubMed]

7. Ojima T, Iwahashi M, Nakamori M, Nakamura M, Katsuda M, Iida T, Hayata K, Yamaue H. Atrial fibrillation after esophageal cancer surgery: an analysis of 207 consecutive patients. Surg Today. 2014; 44:839-847. https://doi. org/10.1007/s00595-013-0616-3. [PubMed]

8. Ojima T, Nakamori M, Nakamura M, Katsuda M, Hayata K, Kato T, Kitadani J, Tabata H, Takeuchi A, Yamaue H. Randomized clinical trial of landiolol hydrochloride for the prevention of atrial fibrillation and postoperative complications after oesophagectomy for cancer. Br J Surg. 2017; 104:1003-9. https://doi.org/10.1002/bjs.10548. [PubMed]

9. Sugiyama A, Takahara A, Hashimoto K. Electrophysiologic, cardiohemodynamic and beta-blocking actions of a new ultra-short-acting beta-blocker, ONO-1101, assessed by the in vivo canine model in comparison with esmolol. J Cardiovasc Pharmacol. 1999; 34:70-77. https://doi. org/10.1097/00005344-199907000-00012. [PubMed]

10. Mori K, Yamada K, Fukuda T, Mitsui T, Kitamura T, Yamaguchi D, Ando J, Wada I, Nomura S, Shimizu N, Seto Y. Landiolol hydrochloride for early postoperative tachycardia after transthoracic esophagectomy. Surg Today. 2014; 44:848-854. https://doi.org/10.1007/s00595-0130615-4. [PubMed]

11. Chin JH, Moon YJ, Jo JY, Han YA, Kim HR, Lee EH, Choi IC. Association between Postoperatively Developed Atrial Fibrillation and Long-Term Mortality after Esophagectomy in Esophageal Cancer Patients: An Observational Study. PLoS One. 2016; 11:e0154931. https://doi.org/10.1371/ journal.pone.0154931. [PubMed]

12. Wells CI, Robertson JP, Campbell S, Al-Herz F, Rhind B, Young M. Impact of atrial fibrillation on long-term survival following oesophagectomy: a 21-year observational study. ANZ J Surg. 2018; 88:E268-272. https://doi.org/10.1111/ ans.14054. [PubMed]

13. Lagarde SM, de Boer JD, ten Kate FJ, Busch OR, Obertop $\mathrm{H}$, van Lanschot JJ. Postoperative complications after esophagectomy for adenocarcinoma of the esophagus are related to timing of death due to recurrence. Ann Surg. 2008; 247:71-76. https://doi.org/10.1097/ SLA.0b013e31815b695e. [PubMed]

14. Rizk NP, Bach PB, Schrag D, Bains MS, Turnbull AD, Karpeh M, Brennan MF, Rusch VW. The impact of complications on outcomes after resection for esophageal and gastroesophageal junction carcinoma. J Am Coll Surg. 2004; 198:42-50. https://doi.org/10.1016/j. jamcollsurg.2003.08.007. [PubMed]

15. Takeuchi M, Takeuchi H, Kawakubo H, Booka E, Mayanagi S, Fukuda K, Nakamura R, Suda K, Wada N, Kitagawa Y. Perioperative Risk Calculator Predicts LongTerm Oncologic Outcome for Patients with Esophageal Carcinoma. Ann Surg Oncol. 2018; 25:837-843. https:// doi.org/10.1245/s10434-017-6311-7. [PubMed]

16. Yamamoto M, Shimokawa M, Yoshida D, Yamaguchi S, Ohta M, Egashira A, Ikebe M, Morita M, Toh Y. The survival impact of postoperative complications after curative resection in patients with esophageal squamous 
cell carcinoma: propensity score-matching analysis. J Cancer Res Clin Oncol. 2020; 146:1351-1360. https://doi. org/10.1007/s00432-020-03173-2. [PubMed]

17. Baba Y, Yoshida N, Shigaki H, Iwatsuki M, Miyamoto Y, Sakamoto Y, Watanabe M, Baba H. Prognostic Impact of Postoperative Complications in 502 Patients With Surgically Resected Esophageal Squamous Cell Carcinoma: A Retrospective Single-institution Study. Ann Surg. 2016; 264:305-311. https://doi.org/10.1097/ SLA.0000000000001510. [PubMed]

18. D'Annoville T, D'Journo XB, Trousse D, Brioude G, Dahan L, Seitz JF, Doddoli C, Thomas PA. Respiratory complications after oesophagectomy for cancer do not affect disease-free survival. Eur J Cardiothorac Surg. 2012; 41:e66-73. https://doi.org/10.1093/ejcts/ezs080. [PubMed]

19. Ferri LE, Law S, Wong KH, Kwok KF, Wong J. The influence of technical complications on postoperative outcome and survival after esophagectomy. Ann Surg Oncol. 2006; 13:557-564. https://doi.org/10.1245/ ASO.2006.04.040. [PubMed]

20. Maesen B, Nijs J, Maessen J, Allessie M, Schotten U. Post-operative atrial fibrillation: a maze of mechanisms. Europace. 2012; 14:159-174. https://doi.org/10.1093/ europace/eur208. [PubMed]

21. Sakamoto A, Yagi K, Okamura T, Harada T, Usuda J. Perioperative Administration of an Intravenous BetaBlocker Landiolol Hydrochloride in Patients with Lung Cancer: A Japanese Retrospective Exploratory Clinical Study. Sci Rep. 2019; 9:5217. https://doi.org/10.1038/ s41598-019-41520-7. [PubMed]

22. Cole SW, Nagaraja AS, Lutgendorf SK, Green PA, Sood AK. Sympathetic nervous system regulation of the tumour microenvironment. Nat Rev Cancer. 2015; 15:563-572. https://doi.org/10.1038/nrc3978. [PubMed]

23. Wang HM, Liao ZX, Komaki R, Welsh JW, O'Reilly MS, Chang JY, Zhuang Y, Levy LB, Lu C, Gomez DR. Improved survival outcomes with the incidental use of beta-blockers among patients with non-small-cell lung cancer treated with definitive radiation therapy. Ann Oncol. 2013; 24:13121319. https://doi.org/10.1093/annonc/mds616. [PubMed]
24. Barron TI, Connolly RM, Sharp L, Bennett K, Visvanathan K. Beta blockers and breast cancer mortality: a populationbased study. J Clin Oncol. 2011; 29:2635-2644. https://doi. org/10.1200/JCO.2010.33.5422. [PubMed]

25. Melhem-Bertrandt A, Chavez-Macgregor M, Lei X, Brown EN, Lee RT, Meric-Bernstam F, Sood AK, Conzen SD, Hortobagyi GN, Gonzalez-Angulo AM. Beta-blocker use is associated with improved relapse-free survival in patients with triple-negative breast cancer. J Clin Oncol. 2011; 29:2645-2652. https://doi.org/10.1200/JCO.2010.33.4441. [PubMed]

26. Powe DG, Voss MJ, Zänker KS, Habashy HO, Green AR, Ellis IO, Entschladen F. Beta-blocker drug therapy reduces secondary cancer formation in breast cancer and improves cancer specific survival. Oncotarget. 2010; 1:628-638. https://doi.org/10.18632/oncotarget.197. [PubMed]

27. Diaz ES, Karlan BY, Li AJ. Impact of beta blockers on epithelial ovarian cancer survival. Gynecol Oncol. 2012; 127:375-378. https://doi.org/10.1016/j.ygyno.2012.07.102. [PubMed]

28. Sawabata N, Funaki S, Hyakutake T, Shintani Y, Fujiwara A, Okumura M. Perioperative circulating tumor cells in surgical patients with non-small cell lung cancer: does surgical manipulation dislodge cancer cells thus allowing them to pass into the peripheral blood? Surg Today. 2016; 46:1402-1409. https://doi.org/10.1007/s00595-016-1318-4. [PubMed]

29. Dindo D, Demartines N, Clavien PA. Classification of surgical complications: a new proposal with evaluation in a cohort of 6336 patients and results of a survey. Ann Surg. 2004; 240:205-213. https://doi.org/10.1097/01. sla.0000133083.54934.ae. [PubMed] 